\title{
Bowie Musicology: Mapping Bowie's Sound and Music Language Across the Catalogue
}

\author{
Leah Kardos
}

Department of Music, Kingston University, London, United Kingdom

\section{L.Kardos@kingston.ac.uk}

2006 Coombehurst House

Kingston-Upon-Thames

Surrey, KT2 7LB

United Kingdom

\begin{abstract}
David Bowie's music career is one marked by dramatic image transformations and unexpected and frequent aesthetic changes. However, if we look beyond the surface and analyse Bowie's back catalogue for patterns and trends in his songwriting methodology, we can start to see evidence of a consistent creative voice that has been present and evolving throughout. This music language uses vocal articulations, idiosyncratic approaches to melody and harmony, mode and tonality, familiar and foreign sonic landscapes and nostalgic references to encode meanings beyond the lyric and immediate pop/rock style representation. Practices and processes that lead to the creation of shared meanings are located in the communicative exchange between creator and listener, a conversation that occurs at the intersection of Production and Consumption.
\end{abstract}

Keywords: David Bowie, composition; production, song writing, semiotics, meaning, consumption. 


\section{Bowie Musicology: Mapping Bowie's Sound and Music Language Across the Catalogue}

During a career spanning over five decades, David Bowie wrote, performed, produced and released 28 studio albums, 5 EPs, over 100 singles - altogether over 350 recorded tracks (not counting numerous B-sides and forthcoming material due for posthumous release). In addition to the music he was also an accomplished visual artist - a painter, a skilled physical performer and actor, a pop polymath whose multimode creativities inspired generations of artists and performers to be bold and 'turn to face the strange'. The V\&A's touring exhibition of Bowie related objects and memorabilia, David Bowie is, chose to highlight the apparent mutability and versatility of the Bowie persona in its title and associated marketing. "David Bowie is __ "works well as a framing device for discussing the content of the archive; it's an unfinished sentence, an invitation for the patrons of the exhibit to provide their own, more personally situated answer. "Bowie emerges as an aesthete and a rebel..." said Peter Bradshaw for the Guardian (2014). "Boundary-pushing performance artist, sexual icon” announced Dan Hyman for Rolling Stone (2014). Certainly in the context of cultural production these qualities have important economic value, particularly in selling the outrageous to postwar teens. However, in discussing what and who David Bowie is, rarely are his skills as a musician and composer upheld in a similar way, despite the size and quality of his catalogue and the critical and commercial success he achieved with it.

These recordings, created as products for purchase and consumption, represent more than a mere economic process at work within the music industrial complex - they are also cultural artefacts. When considering the production of material cultural phenomena, Du Gay $(1997,8)$ reminds us that the economic and the cultural are, in their 'contemporary manifestations', irrevocably entangled: you can't separate the 
cultural artefact from the "economic processes and forms of organisation" that created it; the activities of consumption, and the meanings and values that flow from these, are intimately tied to both (3). The recorded pop song is a unique cultural product in the sense that it seeks to make an object out of something that is non-material, or as Simon Frith observes, "this intangible, time-bound aural experience cannot be touched or held" $(2001,26)$. It used to be the case that for a musical product to be saleable it needed to be stored in some manner of physical container: a vinyl record, cassette tape or compact disc. This naturally lead to a sense of the container representing the record, together becoming a singular object; the cover artwork, the liner notes, the feel and weight of the media itself - these tactile music delivery systems have historically helped us to conceptualise audio recordings as art objects as well as art experiences. That magical combination of sound + vision is something that Bowie has played with throughout his career, taking care to offer not only new and exciting music ideas via his recordings, but also via well-conceived visual signifiers.

Fans know that the music's meaning is enriched by these visual cues: we imagine how Ziggy looks when we hear the songs from The Rise and Fall of Ziggy Stardust and the Spiders from Mars - in my mind, like some cat from Japan looking utterly fantastic in Kensai Yamamoto. At the announcement of a new album or single we might have immediately wondered, what does he look like? How is his hair? Not because we're shallow - it's actually an important consideration because it has always been one of his considerations, it's always meant something (see Mills 2015; Peraino 2012; Harrick 2008; Frith, Goodwin and Grossberg, 1993).

Much has been made of various personae and different stylistic periods in Bowie's career timeline; moments that denote a shift in musical and visual style. Ziggy Stardust, Plastic Soul, The Thin White Duke, the Berlin period, and so on - each of 
these headings comes with its own set of classifications: what he looked like at the time, where he lived in the world, his personal politics, where he was drawing his influences and ideas from - the information that informs how we make sense of what we hear. Mapping the catalogue in such a way is useful for this purpose of understanding various different aesthetic foci and contextualising songs and albums against the timeline. It also divides the body of work into chunks (the Berlin Period, the Tin Machine years, the 80 's, etc) where sweeping value judgements are easy to apply; where it is easy to lose sight of the whole body of work, its ecology, and any sense of it being a continuous flow of creativity, one thing following the other and leading to the next.

As a result, a lot of attention has been paid to Bowie's many changes, however the ways in which Bowie's outputs have remained the same tend not to receive as much attention from scholars and critics. "There's a very strong continuity to the work I do," Bowie said in 2002, "the sensibility of the lyric from 'Space Oddity (1969) is really no different from something from Heathen (2002)...” (Bream 2004). In Strange Fascination: David Bowie: the Definitive Story (2005) biographer David Buckley encourages the reader to look "beneath the musical form (whether it be pop, rock, soul or drum'n'bass)" to the "threads of continuity" that run throughout the body of work, later adding "(his) fans and the critics have... simply on occasion been fooled by the musical and visual shape-changing" (487-8).

In this article I wish to focus on such threads of continuity, and explore some methods of mapping signifying practices across the catalogue, away from any gaze, and without dividing the work into sections of more or less value. My intention is to highlight the sophistication and consistency of Bowie's songcraft throughout - not only as found in the commercial hits, but also in the more obscure and less popular music of 
the catalogue - to encourage exploration and understanding of the quality and substance of his art. From this viewpoint we can discover a fascinating landscape: a uniquely stylised musicianship with recurring sounds, figures and features; sophisticated techniques in music composition; a personally developed, referential sound and music language or representational system (Hall 1997d). With Bowie's music, the culture is not the catalogue itself, but the systems, processes and practices that created it, and the meanings that are created and exchanged at the intersection of Production and Consumption.

\section{Music Semiology, Timbre and Media Literacy}

Thinking about music as analogous to language is by no means a new idea (see Becker 1981; Dowling 1968; Kippen 1987; Jackendoff 1985; Feld and Fox 1994), and music semiology, a method adapted from the study of linguistics, provides a way of conceptualising and analysing musical meaning as communication via signs and gestures. As an analytical tool to aid the understanding of popular music, it has been adopted by musicologists such as Philip Tagg (1982, 2012), Peter Dunbar-Hall (1991) and David Machin (2010), amongst many others and it allows for the musical elements (harmony, melody, rhythm, tonality, etc.) to be considered alongside the timbral, textural, spectral and spatial elements of audio recordings - elements that are very difficult, if not impossible to notate, visualise or meaningfully represent using standard systems. This approach is useful in that it treats the recording as the primary text (as opposed to a written score or published song sheet), and it acknowledges the sonic elements of the song's performance and production as being intrinsic to the products' message. The semiological analysis of music also allows for the possibility that any number of these elements could be used to represent extra-musical (or as Philip Tagg might say, 'paramusical') ideas. As a methodology for analysis and interpretation, this 
approach sits well with Stuart Hall's ideas around language, representation and his constructivist conceptualisation of culture as being about shared meanings and the ways in which these meanings are produced (Hall 1997b). Hall also reminds us that while the semiotic approach might imply a linear 'sender/message/receiver' process, it is also useful to conceive of these encoding/decoding processes as occurring within the circuit structure that is "produced and sustained through the articulation of linked but distinctive moments - production, circulation, distribution/consumption, reproduction" (Hall 1980, 128). In the case of Bowie's musical and sonic representational system, communication is not transparent nor guaranteed to be received in a consistent way, but rather meaning is constructed in the dialogue between these "encoding and decoding moments" (Hall 1980, 136).

The sound languages associated with various scenes and genres of recorded music are constantly evolving under the influence of developing technology and the zeitgeist. In Music, Language and the Brain (2010), Aniruddh Patel outlines two distinct sound systems that we are born into and grow to become literate in: the first is linguistic, the second a musical sound world that we're exposed to, the "timbres and pitches of the culture's music" (9).

Timbre, a word by which we refer to the quality or tone colour of a sound, is a property inextricably linked with communication and memory. In This is Your Brain on Music (2006) Daniel Levitin states that timbre is the "most important and ecologically relevant feature of auditory events", and the "principal feature that distinguishes the growl of a lion from the purr of a cat, the crack of thunder from the crash of ocean waves" (45). He goes on to state that our ability to identify differences in timbre is so acute that it allows us to recognise "hundreds of different voices" to the point of being able to discern whether "someone close to us - our mother, our spouse - is happy or sad, 
healthy or coming down with a cold, based on the timbre of that voice" (54).

In a live musical performance, timbres are interpreted in the moment as music messages are streamed past us in real time. They can never be repeated in exactly the same way again - the variables of environment, performance, chance and human error combine to create a unique experience. One of the enchanting features of score-based music is the ephemeral nature of its existence, the endless potential for different performed experiences of it. In an audio recording timbres are inscribed definitively, and the ability to play back the music more than one time means that these spectral details can be analysed up close, pored over, understood in a different way. This is one of the reasons recorded music has the capability of accumulating extra-musical baggage: timbral memories give us the ability to recall sounds and samples from other places; production vernacular can situate new musical ideas in a different time-space; reference, self-quotation and other hauntological production techniques can add layers of meaning to a musical statement, mediating between past and present.

In Understanding Popular Music (1994), Roy Shuker writes about the necessity of a 'critical media literacy' in order to effectively appreciate the context of popular music. This, he says, comes about through the process of actively and passively reading the popular media that saturates society (8). In Distinction (1984), Bourdieu points out that it is our accumulated cultural knowledge that gives pleasure to the reading of cultural texts. Nate Harrison echoes this idea when he refers to the "collective audio subconscious" (Harrison 2014), where shared meanings exist because of shared exposure to media cultures.

This notion can be downscaled to a 'critical Bowie literacy', too. You don't need to be a musicologist or an anorak to appreciate these encoded meanings. Bowie's 
consistent mainstream exposure means that there is a level of literacy achieved in the popular culture at large - an awareness of who he is, what he looks like, what his music sounds like and the timbres of his voice. Consider the bite-sized sample of 'Let's Dance' that plays the moment Bowie turns to the camera during his guest spot in the film Zoolander (2004), or the use of "Heroes" as the unofficial anthem of the London Olympics in 2012, blasting out at every medal ceremony. Since Bowie's passing, mainstream media has increased the amount and intensity of their coverage, further spreading exposure to, and awareness of, his work.

\section{A Topology of Bowie Musicology}

Stuart Hall showed us how meaning does not simply arise from an object's mere existence, but from the "language games and classifying systems into which they are inserted" (Hall 1997a, 221). Cultures are navigated by shared conceptual 'maps of meaning' - thus constantly renewing frameworks that we, the listeners and consumers, create via discourse so that we may make sense of things.

When classifying the musical and sonic features of Bowie's catalogue, we not only consider the raw elements of production, but their appearance and recurrence in the timeline - for example, song materials located within the so-called Berlin Triptych might include the sound of snare drums being processed through Tony Visconti's harmonizer, or the timbres of the EMS Synthi AKS, the unique reverberations of the large hall at Hansa Tonstudio, the ambient-stylistic influence of Brian Eno, and so on. As a result, these practices when repeated outside of their historical setting take on representational weight. As Hall remarked (1997c), “systems of classification are very complex, but without some noting of 'this belongs with that, that is different from this,' we wouldn't be able to have a conceptual map". And it is this map-making that I am 
interested in, a kind of cartography of signifying practices across the catalogue. If Bowie's music productions share a common language, then what features would we be able to recognise as being part of that representational system?

The key to code breaking is discovering the pattern. In surveying Bowie's music work, we look beyond individual lyrical narratives, album concepts and surface style shifts, and take a holistic view of creative practices from Liza Jane (1964) through to Blackstar (2016) - seeking patterns in song craft, creative philosophy and approach, recurring recognisable sonic effects, various different expressive vocal characterisations and articulations, and anything else we can find.

A great hallmark of Bowie's songwriting is his unique gift for melody. It is generally accepted and agreed upon amongst critics and musicologists (particularly in the wake of his passing) that he has penned some of the most lovely and uniquely distinctive melodies ever to grace the popular canon (and if you doubt that claim, I refer the reader to the tender curves of 'Lady Grinning Soul' (from Aladdin Sane), the grandiose architecture of 'Life On Mars?' (Hunky Dory), the cascading strangeness of 'Ashes to Ashes' (Scary Monsters) - three examples chosen arbitrarily out of many worthy contenders).

The melodies in the catalogue are characterful and distinct, yet overall there is a certain Bowieness to these shapes. You can observe them caressing an odd angle long enough to make the strangeness feel natural - for example, the refrain "...oh Ramona", in "The Hearts Filthy Lesson' (1. Outside) and "Can't turn around no, can't turn around no", in 'DJ' (Lodger) both jump to an unexpected pitch and stubbornly stay there to carve out a hook. The phrase might land on a dissonant note and teasingly deny a resolution, like in the line "Cos you can never really tell when somebody wants something you want too", 
from 'Stay' (Lodger), or “At the center of it all, your eyes”, from 'Blackstar'

(Blackstar). Elsewhere melodies might leap dramatically to an unexpected interval (“As I ask you to focus on sailors fighting in the dance hall, oh man...", in 'Life On Mars?'(Hunky Dory), "Look for the cars or signs of life", in 'Sunday'(Heathen)), or hold constant on long notes that sail over the top of quick paced chaos ("I need you flying”, in 'Saviour Machine' (The Man Who Sold The World), "Poor dunce”, in 'A Small Plot of Land' (1. Outside), "You went with that clown", in 'Sue (Or In A Season Of Crime)' (Blackstar)). In 'Let's Dance' (Let's Dance), we get both the declaring top phrase and an extension of it that lingers afterwards in the recesses: "Let's dance / Put on your red shoes and dance the blues" - this approach can be observed elsewhere for example in 'Sons Of The Silent Age' ("Heroes”) ("Search through their one inch thoughts then decide it couldn't be done") and 'New Angels Of Promise' (hours...) ("We are the fabulous lovers / I am a blind man she's my eyes").

Part of the magic is in the disruption of expectations. A standard approach in Western tonal music traditions is to build melodic phrases into 'arch' shapes (see Adams 1976; Edworthy 1985; Huron 1996), ascending towards moments of heightened intensity and then receding. There are instances of arch shaped phrasing in Bowie's songwriting ('Absolute Beginners' - Bowie's theme tune to the 1986 film of the same name is a good example), however we more often see him carving out a different line: throwing his voice like a javelin, hitting a mark with energy and intensity and spiraling downward from there. Figure 1 is a visual representation of some examples that follow this trend. Gestural features of the melodic line are shown on a stave, the height, flow and darkness of the line relating to relative pitch and intensity (a graphical idea stolen from Middleton 1993, 182). The bar lines mark out time intervals of four beats. 
[Figure 1. Inserted Here]

Figure 1. Examples of melodic contour and trajectory in 'Karma Man' (1976), 'Sons Of The Silent Age' (1977), 'Look Back In Anger' (1979), 'Ashes To Ashes’ (1980), 'The Voyeur Of Utter Destruction (As Beauty)' (1995), and 'Lazarus' (2016).

Another striking feature of the catalogue is the range of vocal styles and timbres that Bowie deploys in the performance of his melodies. Sometimes he sings with an exaggerated London accent ('Scary Monsters (and Supercreeps)' (Scary Monsters)) at other times it might be something more theatrical ('Fill Your Heart' (Hunky Dory)), histrionic (helpfully identified by Tony Visconti (quoted in Wilson, 2016) as the loudest vocal sections of 'Heroes' ("Heroes”)), off kilter (the unbalanced eccentricity of 'We Prick You' (1.Outside) or 'Girl Loves Me' (Blackstar)), hushed ('Without You' (Let's Dance)), seemingly emotionally detached ('Always Crashing In The Same Car' (Low)), frail ('The Loneliest Guy' (Reality)) or perhaps something sounding very much like a Scott Walker impression ('The Motel' (1.Outside)) - and more, a motley collection of diverse vocal articulations and characterisations that seem to serve performative and communicative purposes.

In classifying and mapping these qualities one might wish to create a system where Bowie's use of various voices was plotted along a continuum ranging from seemingly unaffected to completely self-reflexive. While a melody line or chord progression is more or less quantifiable, identifying vocal tones and articulations (and reading/assigning meanings to these qualities) is less clear-cut.

As ever with the analysis of music's meaning, all we have to work with is our own perception (Olwage 2004), and the way in which we process and balance the information coming at us from multiple sources: the text, the music, its performances and aesthetics, the technological, historical, social and economic conditions of its 
production (Moore 2001). Classifying Bowie's vocalisations based on individual perception will return subjective results, but as a map-making exercise it would be useful if it can make visible patterns and trends that could help us better understand and contextualise these as signifying practices against the rest of the song information. Advancements in music machine listening ${ }^{1}$ may soon provide access to algorithms that can identify specific timbral differences of a vocal that is embedded within an arrangement, bringing aspects of this work back into the realm of the objective. Not content to wait for such technology, I set up a classifying system for this purpose. A simple dataset was created that tagged each song in the catalogue with a general lyrical theme, a prevalent voice type (if any), and other information of interest (year of release, style references, what kind of key or mode the song is in, etc.). This information was used to create basic data visualisations that allowed me to filter and view these properties in interesting combinations.

The visualisations were generated using the free software application Tableau Public $^{2}$, and the set that I refer to here (both the visualisations and data) is permanently available online to view, download and edit (Kardos 2016). The analysis is not meant to generate necessarily definitive results but rather be an ongoing exploratory and collaborative exercise in map making and perception. Over time I have fiddled with the data when I've changed my mind or lost a debate and have invited people to collaborate and suggest improvements. The dataset I'm referring to here is the latest available at the time of writing ${ }^{3}$. Figure 2 shows vocal styles represented across the catalogue (with instrumental tracks filtered out of the dataset). Figure 3 shows the use of these voices across time. The voice style that I classified as being 'direct' (a term by which I specifically mean without dramatic effect or theatricality, what I referred to earlier as the seemingly unaffected end of the spectrum, exemplified by tracks such as 
'Conversation Piece' (1969) and 'Afraid' (Heathen), is the most prevalent with 53 examples, but coming a close second is the 'mixture' classification (51 examples), those instances where I perceived the use of two or more different voice types in the one song. This illuminates the fact that throughout the catalogue there are nearly as many songs that I detect multiple vocal characterisations in as there are songs, which seem (to me) to ignore the idea altogether. Across time (Figure 3) I can observe how my idea of Bowie's emotionally 'detached' voice first appears in 1974 on the Diamond Dogs outtake 'Alt. Candidate', and is used more frequently during the Berlin era (on songs such as 'Breaking Glass' (Low) and 'Repetition' (Lodger), disappears after Scary Monsters (And Super Creeps) and re-emerges in the late 80s with Tin Machine ('I Can't Read'). The times when Bowie sings in a 'quasi-Caribbean' accent are strictly limited to the middle zone on the chart, 1984 and 1993, and in such rare instance it's tempting to think he might have been aware of how ill-advised it was. In other perspectives of the dataset, it looks as though different Bowie voices inhabit certain lyrical-thematic territories (Figure 4), though there is a lot of overlap. For me, the value in this classification system is in being able to see occurrences of signifying practices through different frames.

[Figure 2 Inserted Here]

Figure 2. Vocal styles represented across the whole catalogue.

[Figure 3 Inserted Here]

Figure 3. Vocal styles represented over time.

[Figure 4 Inserted Here] 
Figure 4. Instances of voices singing about 'Sex', 'Death' and 'Age'.

Without getting too esoteric with the musicological terminology, and being without the space in this article to engage in lengthy theoretical proofs to back up my claims, I feel it is safe to say that the harmonic detail and tonal colour of Bowie's music, generally speaking and when juxtaposed against the popular music of its time, shows uncommon sophistication (an idea generally supported by Ian Chapman in Experiencing David Bowie: A Listener's Companion (2016)). This is certainly not music written to the Blues template in the manner of Bolan or the Stones. This is a harmonic language informed by music hall, musical theatre, contemporary experimentalism, soul music, and much more.

Beyond plain major and minor keys, Bowie's frequent use of modes can add an air of exoticism and/or appropriate strangeness to the proceedings. Mixolydian mode is a common rock $\mathrm{n}$ roll tonality that features a flattened $7^{\text {th }}$ degree that lends chord progressions a characteristic toughness - its effect can be heard in 'Rebel Rebel' (Aladdin Sane), 'Golden Years' (Station to Station), "Heroes" ("Heroes"), 'Day-In Day-Out' (Never Let Me Down), 'Jump They Say' (Black Tie White Noise), 'Dead Man Walking' (Earthling), and 'New Killer Star' (Reality). The Phrygian mode is a variation on the minor scale that produces a dark, middle-eastern sounding effect with its flattened $2^{\text {nd }}$. Examples of songs that use the Phrygian modal effect include 'Yassassin' (Lodger), 'Video Crime' (Tin Machine), 'A Small Plot of Land' (1. Outside), 'I'm Deranged' (1. Outside), 'Brilliant Adventure' (hours...), and 'Blackstar' (Blackstar). The Lydian mode is a major scale with a sharpened $4^{\text {th }}$ degree and relatively rare to find in pop music (the characteristic Lydian modal effect is famously used in the opening notes of the themes to The Simpsons and The Jetsons). Bowie uses it in songs such as 
'Warszawa' (Low), 'Sons of the Silent Age' ( “Heroes”), 'Repetition' (Lodger), 'Untitled No. 1' (The Buddha of Suburbia), 'Leon Takes Us Outside' (1. Outside), 'Hearts Filthy Lesson' (1. Outside), and 'Sue (or in a Season of Crime)' (Blackstar).

Bowie's chord progressions, even in his most straight up-and-down rock songs, are rarely straight up-and-down. Consider for a moment the first three chords of 'Moonage Daydream' (Ziggy Stardust): D major (“I'm an alligator”) F\# major (“I'm a mama-papa callin' for you") and B minor (“I'm a space invader..."). In music theory we would call the middle chord a secondary dominant - a harmonic device that creates a temporary shift to a new key, in this case, the relative B minor. Within the first three chords, Bowie has shifted the firmament. The effect of these harmonic/tonal shifts is slightly dizzying, kind of exhilarating. See also the B section of 'Soul Love' ("Love is careless in its choosing...", also from Ziggy). When have you heard sophisticated diatonic harmony rock so hard?

Elsewhere there are clues that Bowie uses specific chords, colours and sounds as signifiers. The opening guitar chords of 'Space Oddity' (from the self-titled 1969 album) are something of a vernacular sound in pop culture now, with a murky dissonant quality due to the way the F Major7 chord has been voiced by the 12 string guitar. The undulation of the opening progression (from F Major 7 to Em) is simultaneously dreamy and menacing and we are soon given information about Major Tom's narrative, which gives us an opportunity to contextualise these sensations and create some meaningful connections: outer space, wonder, danger, loneliness, passivity, floating separately to the world, looking down on it as an outsider. When a similar sound is heard briefly during the opening strains of 'Starman' ("Hey now now”, track 4 from from Ziggy), is Bowie using it as a signifier to invoke that sense of wonder and menace that Major Tom (and listeners) felt back in 1969? Decades later in Tin Machine's 
'Amlapura' (from Tin Machine II) there are echoes of it again, this time less murky, now perfuming a dreamscape; gazing not to the stars but towards the spiritual, in a neat 2001 A Space Odyssey/'Space Oddity' circle.

'Buddha of Suburbia' (from the 1993 soundtrack album The Buddha of Suburbia) directly quotes the recognisable guitar riff from 'Space Oddity' in addition to lines from 'All The Mad Men' (The Man Who Sold The World). Here we reliably see Bowie communicating with signifiers plucked from his catalogue, presumably to enrich and intensify the encoded meanings within the song. Just as the meaning making processes operating in any one site of the Circuit of Culture are dependent upon the others, the song content and cultural environment of 'Buddha of Suburbia' provides affordances and practices from different locations that relate to, and are dependent upon each other. There is the book, The Buddha of Suburbia (Kureishi 2009), a semiautobiographical account of the author's experiences growing up in suburban South London in the 70s, and the four-part drama series by the BBC in 1993, for which Bowie supplied the soundtrack; the obvious parallels to Bowie's personal narrative, himself having also grown up in South London, a connection that naturally lends the song (and its lyric) an autobiographical edge; the direct quotation of recognisable elements of early period songs - songs which also touch on themes of feeling trapped/losing oneself). All of these ideas combine to create a song particularly rich in interconnected meaning.

Elsewhere, Bowie's use of the same techniques is not as clear-cut. I'm still feeling baffled by the appearance of 'Woody' Woodmansey's 'Five Years' drum pattern (the signaling first sounds of The Rise and Fall of Ziggy Stardust and the Spiders from Mars) in the closing moments of 'You Feel So Lonely You Could Die' (The Next Day), lyrically one of the darkest songs Bowie has ever written. There's the throwaway 
reference to 'Changes' (Hunky Dory) ahead of the trumpet solo of 'You've Been Around' (Black Tie White Noise) - more of a wink at the audience than anything else. In 'I Can’t Give Everything Away' (Blackstar), the opening strains of the harmonica line from the B section of ‘A New Career In A New Town’ (Low) are clearly heard, associating ideas of transition and frontiersmanship with a song that seems to speak directly about dying and making candid final confessions.

On a subtler level, it seems as though 'I Can't Give Everything Away' is haunted by more ghosts: the harmonica line also bringing to mind the opening strains of 'Never Let Me Down' (from the album of the same name), a notable song for its honest and emotionally genuine sentiment of gratitude. If you follow the contour of the melody, you might find it traces some the shapes from 'Soul Love' whose lyrics in turn speak of headstones, graves, new love, babies, God, love and loneliness. Finally, the initial burst of sound at the start of the track - the starting instrumental texture that is dominated by a synthetic string effect - to my ear, recalls the same first moments of 'Thursdays Child' (from 'hours... '), but pitched a semitone lower. Go ahead and play the opening of one and then the other before you scoff. More interconnectedness to consider, more knots to unpick.

\section{Shifting Discourse}

\footnotetext{
“Taking the present philosophical line we don't expect our audience to necessarily seek an explanation from ourselves. We assign that role to the listener and to culture. As both of these are in a state of permanent change there will be a constant "drift" in interpretation. All art is unstable. Its meaning is not necessarily that implied by the author. There is no authoritative voice. There are only multiple readings." (Bowie 1995)
}

"There is no escape from the fact that meaning is, in the end, interpretation. It is always contextual." (Stuart Hall, 'Representations in the Media' lecture, 1997(c)) 
Allen F. Moore identified a potential problem with music analysis, in as much as it requires us to assemble meaning from listening to something, an experience that is personal, physical, and "at root... subject to interpretation" $(2003,6)$. We know individual interpretations can be at times unreliable, debatable, even contestable, and interpretative analysis can sometimes be guilty of reading images and ideas into things that may not be there. No single opinion is right or complete. Between the ideas communicated to us by the artist through the work itself, us talking about and sharing our interpretations, and our continually building knowledge of culture and context, we create a conversation at the intersection of Production and Consumption. Here is where meanings are made (and argued about - one of the principal pleasures of pop music discourse). Even when aspects of analysis are objectively quantifiable, as is the case with melodic lines and chord changes - when isolated from the song's context (lyric, arrangement, performance, production) they yield little useful meaning. To make sense we must use multiple layers of information to construct, and if necessary deconstruct and reassemble these meanings based on consensus, cultural context or changing circumstances

Blackstar was released on the 8th of January 2016, two days before the day Bowie died. With the public revelation of his death, the album's meaning shifted quickly and dramatically. The consensus of interpretations seemed to agree that what had previously felt like a poetic and stylistically adventurous collection of songs (critic Alexis Petridis described it as "lyrically inscrutable and thrillingly strange", 2016), now had a fresh, stark clarity: he seemed to be communicating directly about his terminal illness. He seemed to be saying goodbye. The symbols, language, references fell into place for many, like a macabre puzzle box where the final piece needed to solve it was provided with Bowie's passing. The tone and content of discourse around the album 
changed. The Guardian, who published Kitty Empire's review the day before news broke of his death (4 stars) (2016(a)), invited the reviewer back to reappraise the album with the benefit of hindsight (2016(b)). The dramatic schism in context brought about by Bowie's passing has meant that for many, Blackstar possesses two sets of meanings before and after January $10^{\text {th }}, 2016$.

\section{Conclusion}

The purpose of this article is not to tell you how you ought to listen to Bowie records, and I'm certainly not trying to suggest that the best way to appreciate Bowie's music is to acquire an encyclopedic knowledge of it. Bowie's musical cultural phenomena can approached via multiple access points: from the radio hits to the deep cuts to an understanding of Bowie's musical language games and further into the realms of the obsessives. We construct meaning when we consume these products because we contextualise and make sense of what we perceive against the culture that we know. The Bowie culture that we have helped to construct by being participants in this exchange.

This article focuses on a specific area of Bowie's cultural production - the music of his catalogue, not taking into account the institutions and other systems of production (record labels, publishing, marketing, funding and sponsorship, etc), or the historical, industrial conditions that led to its creation. Also beyond the remit for this discussion, but still a point worthy of exploration, is the idea of 'production for profit' commerciality, courting mainstream success and 'selling out'. There is a lot more to say about how Bowie is musically produced - the impact of music technology, experimentalism, key collaborative relationships, touring performances, the Internet. By keeping the focus tightly on Bowie's approaches to songcraft and looking at ways of mapping signifying practices within it, I have sought to articulate, in an intertextual 
way, the meaning-making discourse between art object and interpretation, production and consumption. I have also sought this opportunity to spotlight Bowie's skill and sophistication as a composer, performer and producer of music.

Bowie's musical outputs produced meanings about himself, his philosophies, intellectual, emotional and futuristic worlds, through the encoding of ideas using the languages of music, text, sound, and memory. Bowie's songwriting practices encode meaning through the crafting of lyrics, melodies, harmonies, structures and textures. The consumption of Bowie's musical products creates meaning through the social creation of myths and memes, by becoming attached to history and embedded in memory, by accumulating extra-musical 'baggage'. In listening to and decoding these messages, we can recognize, analyse, categorise and quantify - constructing our sense of identity through the direct experiences music offers, allowing us to inhabit "imaginative cultural narratives" (Frith 1996, 124, paraphrase). Together we construct meaning by cracking Bowie's code and debating the intent behind his methods: melodies and harmonies, references, gestures and textures; ghosts, echoes, presence, absence, difference, the meanings of disrupted expectations; memories, nostalgia, emotions and the connecting of ideas and feelings across time and space. In this our engagement with Bowie's life's work rewards us with new ways of seeing and understanding; fresh pleasures from the text. 


\section{Endnotes:}

1. Machine Listening is a growing, interdisciplinary research field that seeks to develop technology that can extract meaningful information from audio signals. It is thought that perceptual mechanisms located and occurring in the human ear/brain can be simulated, offering potential for a computer to hear and understand audio content.

2. Tableau Public is a free software application that allows spreadsheet data to be turned into visualisations. http://public.tableau.com

3. All changes to the dataset are logged on the downloadable spreadsheet, and the latest version of the spread sheet is permanently located here:

http://www.leahkardos.com/resources/Bowie-Data.xls 


\section{References:}

Adams, Charles R. 1976. "Melodic Contour Typology." Ethnomusicology 20 (2): 179215.

Auslander, Philip. 2006. Performing glam rock: gender and theatricality in popular music. Ann Arbor, MI: University of Michigan Press.

Barthes, Roland. 1977. The Grain of the Voice. In Image, Music, Text, translated by Stephen Heath, 179-89. London: Fontana.

Becker, Judith, and Alton Becker. 1979. "A Grammar of the Music Genre 'Srepegan'.” Journal of Music Theory 23 (1): 1-43.

Bourdieu, Pierre. 1984. Distinction: A Social Critique of the Judgement of Taste. Cambridge, MA: Harvard University Press.

Bowie, David. 1995. Manuscript notes on 1. Outside. The David Bowie Archive.

Bradshaw, Peter. 2014. “David Bowie Is Review - Bowie's Brilliance Shines in StarStudded Tribute." The Guardian, November 13. http://www.theguardian.com/film/2014/nov/13/david-bowie-is-reviewdocumentary

Bream, Jon. 2004. "Hunky Dory; All is well with David Bowie After Battling the Flu and the Burden of his Own Legacy." Minneapolis Star Tribune, 9 January. http://www.highbeam.com/doc/1G1-112031588.html

Buckley, David. 2012. Strange Fascination: David Bowie: The Definitive Story. London: Random House.

Clarke, Eric F. 2005. Ways of Listening: An Ecological Approach to the Perception of Musical Meaning. Oxford University Press.

Chapman, Ian. 2016. Experiencing David Bowie: A Listener's Companion. United States: Rowman \& Littlefield.

Deutsch, Diana. 1999. “Grouping mechanisms in music.” In The psychology of music, edited by Diana Deutsch, 299-349. San Diego, CA: Elsevier.

Dowling, W. Jay, and Dane L. Harwood.. 1986. Music Cognition. Orlando, FL: Academic.

Du Gay, P. (ed.) 1997. Production of Culture/Cultures of Production. Thousand Oaks, CA: Sage.

Dunbar-Hall, Peter. 1991. "Semiotics as a Method for the Study of Popular Music." International Review of the Aesthetics and Sociology of Music 22 (2): 127-132. 
Edworthy, Judy. 1985. "Melodic Contour and Musical Structure." In Musical Structure and Cognition, P. Howell, I. Cross \& R West, Eds. 169-188. London: Academic Press.

Empire, Kitty. 2016(a). "David Bowie: Blackstar Review - Urgent, Contemporary and Elliptical." The Guardian, January 10. http://www.theguardian.com/music/2016/jan/10/david-bowie-blackstar-reviewjazz-group

Empire, Kitty. 2016(b). "I Thought Lazarus was David Bowie's Latest Guise..." The Guardian, January 24. http://www.theguardian.com/music/2016/jan/24/david-bowie-blackstar-albumdeath-references-lazarus-reappraisal

Feld, Steven, and Aaron A. Fox. 1994. "Music and language." Annual Review of Anthropology 23: 25-53.

Frith, Simon, Andrew Goodwin, and Lawrence Grossberg, eds. 1993. Sound and Vision: The Music Video Reader. New York: Taylor \& Francis.

Frith, Simon. 1996. "Music and identity." In Questions of Cultural Identity, edited by Stuart Hall and Paul du Gay. 108-127. London: Sage.

Frith, Simon. 2001. "The popular music industry." In The Cambridge Companion to Pop and Rock. 26. Cambridge: Cambridge University Press.

Hall, Stuart. 1997(a). "The Centrality of Culture: Notes on the Cultural Revolutions of our Time." In Media and Cultural Regulation, edited by K. Thompson. 207-238. London: Sage.

Hall, Stuart. 1997(b). “Culture, Media and Identities.” In Representation: Cultural representations and signifying practices, edited by Stuart Hall. London: Sage.

Hall, Stuart. 1997(c). "Representation \& The Media." Lecture presented at the University of Westminster, London, transcribed by Sut Jhally. Northampton MA: Media Education Foundation.

Hall, Stuart. 1997(d). Representation: Cultural Representations and Signifying Practices Thousand Oaks, CA: Sage.

Hall, Stuart. 1980. "Encoding/decoding." In Culture, Media, Language: Working Papers in Cultural Studies 1976-79. New York: Routledge. 128-138.

Harrison, Nate. 2014. "The Amen Break." In The Routledge Companion to Remix Studies, E. Navas, O. Gallagher \& X. Burrough, eds. 444. New York: Routledge. 
Huron, David. 1996. "The Melodic Arch in Western Folksongs." Computing in Musicology 10: 3-23.

Hyman, Dan. 2014. “'David Bowie Is' Incredible: Inside the Enigmatic Star's New Retrospective." Rolling Stone, September 23.

http://www.rollingstone.com/music/features/david-bowie-is-museumretrospective-20140923

Jackendoff, Ray. 1985. A Generative Theory of Tonal Music. Cambridge MA: MIT Press

Kardos, Leah. 2016. General Bowie Vocalisations Vs. Song Content (database, accessed March 31, 2016).

https://public.tableau.com/views/GeneralBowieVocalisationsvsSongContent/Vo calStylesAcrossCatologue

Kureishi, Hanif. 2009. The Buddha of Suburbia. London: Faber \& Faber.

Kippen James. 1987. "An Ethnomusicological Approach to the Analysis of Musical Cognition." Music Perception: An Interdisciplinary Journal 5 (2): 173-195.

Levitin, Daniel J. 2011. This is Your Brain on Music: Understanding a Human Obsession. London: Atlantic Books.

Machin, David. 2010. Analysing popular music: Image, Sound and Text. London: Sage. Middleton, Richard. 1993. "Popular Music Analysis and Musicology: Bridging the Gap." Popular Music 12 (2): 177-190.

Mills, Richard. 2015. “"Transformer': David Bowie's rejection of 1960s counterculture fashion through his glam reinvention and stylings in the years 1969-1972." Clothing Cultures 2 (2): 179-192.

Moore, Allan F. 1992. "Patterns of harmony." Popular Music 11 (1): 73-106.

Moore, Allan F. 2001. Rock, the Primary Text: Developing a Musicology of Rock. Aldershot: Ashgate.

Olwage, Grant. 2004. "The Class and Colour of Tone: An Essay on the Social History of Vocal Timbre." Ethnomusicology Forum 13 (2): 203-226.

Patel, Aniruddh D. 2010. Music, Language, and the Brain. New York: Oxford University Press.

Peraino, Judith A. 2012. "Plumbing the Surface of Sound and Vision: David Bowie, Andy Warhol, and the Art of Posing." Qui Parle 21 (1): 151-184.

Petridis, Alexis. 2016. "David Bowie: Blackstar Review - A Spellbinding Break with his Past." The Guardian, January 7. 
http://www.theguardian.com/music/2016/jan/07/david-bowie-blackstar-reviewa-spellbinding-break-with-his-past

Tagg, Philip. 1982. “Analysing Popular Music: Theory, Method and Practice.” Popular Music 2: 37-67.

Tagg, Philip. 2012. Music's Meanings: A Modern Musicology for Non-Musos. New York: Mass Media's Scholar's Press.

Wilson, Scott. 2016. "Tony Visconti Working on David Bowie-Inspired Plug-in Effect." Factmag, March 15.

http://www.factmag.com/2016/03/15/david-bowie-plugin-tony-visconti-eventide Zoolander. 2004. Paramount Home Entertainment. 